\title{
Manyetik Dişli Sisteminin Sonlu Elemanlar Yöntemi ile Analizi
}

\author{
Sinan Başaran ${ }^{1 *}$ \\ 1* Bilecik Şeyh Edebali Üniversitesi, Mühendislik Fakültesi, Makine Mühendisliği Bölümü, Bilecik, Türkiye, (ORCID: 0000-0002-3783-2260), \\ sinan.basaran@bilecik.edu.tr
}

(İlk Geliş Tarihi 3 Kasım 2020 ve Kabul Tarihi 11 Ocak 2021)

(DOI: 10.31590/ejosat.820561)

ATIF/REFERENCE: Başaran, S. (2021). Manyetik Dişli Sisteminin Sonlu Elemanlar Yöntemi ile Analizi. Avrupa Bilim ve Teknoloji Dergisi, (21), 37-42.

\section{$\ddot{O} \mathbf{z}$}

Manyetik dişli sistemi sabit mıknatıslar yardımı ile elde edilen manyetik kuvvetler ile çalışan, klasik dişli sistemlerine alternatif olabilecek yapıya sahip bir aktarım elemanıdır. Giriş ve çıkış mili arasında tork iletmek için manyetik dişli sisteminde klasik dişlilerden farklı olarak mekanik bir temas olmadan iletim söz konusudur. Dolayısıyla sürtünme ortadan kaldırılmış olmaktadır. Sürtünmenin ortadan kalkması klasik dişli kutusu sistemlerine göre manyetik dişli sistemlerinin çok daha yüksek verimlerde çalışması manasına gelmektedir. Manyetik dişli sistemlerinde hareket ve tork iletimi temassız olarak gerçekleştiği için hiçbir zaman yağlama gerektirmez ve yağlamadan kaynaklanan sorunlar meydana gelmez. Geleneksel mekanik dişli kutusu sistemlerinde, çevrim oranı kullanılan diş sayısına göre belirlenir. Manyetik dişli sistemlerinde ise benzer olarak, kullanılan sabit mıknatısların sayısı çevrim oranını belirlemektedir. Bu çalışmada koaksiyel bir yapıya sahip manyetik dişli sistemi tasarlanarak sonlu elemanlar yöntemi ile elektromanyetik analizi yapılmıştır. Giriş mili ve çıkış milinde belirli hızlarda eksenel tork değerleri zamana bağlı sonlu elemanlar analizi sonucunda elde edilmiştir.

Anahtar Kelimeler: Manyetik dişli, Sabit mıknatıslar, Eksenel tork, Sonlu elemanlar analizi.

\section{Analysis of Magnetic Gear System with Finite Element Method}

\begin{abstract}
The magnetic gear system works with magnetic forces obtained with the help of permanent magnets and has a structure that can be an alternative to classical gear systems. In order to transmit torque between the input and output shaft, unlike conventional gears, there is a transmission without mechanical contact in the magnetic gear system. Therefore, friction is eliminated. Elimination of friction means that magnetic gear systems operate at much higher efficiency compared to conventional gearbox systems. Since the movement and torque transmission in magnetic gear systems occur without contact, it never requires lubrication and problems arising from lubrication do not occur. In conventional mechanical gearbox systems, the conversion rate is determined by the number of teeth used. Similarly, the number of permanent magnets used determines the conversion rate in magnetic gear systems. In this study, a magnetic gear system with a coaxial structure was designed and its electromagnetic analysis was made with the finite element method. Axial torque values at certain speeds in the input shaft and output shaft were obtained as a result of finite element analysis depending on time.
\end{abstract}

Keywords: Magnetic gear, Permanent magnets, Axial torque, Finite element analysis.

\footnotetext{
*Sorumlu Yazar: sinan.basaran@bilecik.edu.tr
} 


\section{Giriş}

Birçok endüstriyel sistemde boyut ve hacmi azaltarak elde edilebilecek tork değerini arttırmak için çeşitli çalışmalar yapılmaktadır. Klasik yöntem olarak bir elektrik motorunun çıkışındaki tork miktarını arttırmak için klasik mekanik dişli kutusu kullanılmaktadır. Elektrik motorlarında daha büyük bir motor seçmek yerine dişli kutusu koyarak sistem tork çıkışını arttırmak dolayısıyla tork yoğunluğunu arttırmak temel bir tasarım kriteridir. Hız ve moment büyüklükleri ihtiyaç duyulan değerlere yükseltmesi veya alçaltması dişlileri vazgeçilmez kılmıştır. Taşıtlar, rüzgâr santralleri, saat mekanizmaları başta olmak üzere çeşitli endüstri uygulamalarında örnekleri görülebilen bu fiziksel yapılar aşırı yükten, ısınma, sürtünme ve malzemenin yorulmaya maruz kalması gibi olumsuzluklardan büyük zarar görmektedir. Aşırı yüke ve aşırı 1sıya karşı periyodik bakım, yağlama gibi koruyucu önlemler alınmaktadır. Sabit mıknatıslar yardımıyla elde edilen manyetik kuvvet birçok uygulamada aktif olarak kullanılmaktadır. Yeni nesil neodmiyum (NdFeB) kalıcı mıknatıslar artık yaygın bir şekilde temin edilebilmesiyle birlikte elektrik motoru, manyetik levitasyon sistemleri, manyetik kavrama ve manyetik dişli sistemleri gibi birçok sistemde uygulama alanı bulmaktadır.

Manyetik bir dişli, mekanik temas olmadan giriş ve çıkış mili arasında torku iletmek için kalıcı mıknatısların kullanıldığ bir tork aktarım elemanıdır. Benzer tork aktarım sistemlerine kıyasla manyetik dişli, mekanik bir dişliden daha küçük, daha hafif ve uzun vadede bakım gerektirmedikleri için daha düşük maliyetli olacaktır. Klasik dişli sistemlerinden farklı olarak hareketli parçalar arasında mekanik temas olmadığı için aşınma durumu söz konusu değildir dolayısı ile yağlama gerekmez. Yağlamadan ötürü oluşacak olumsuzluklar manyetik dişli uygulamalarında devre dişı bırakıldığı için temiz oda uygulamaları, gıda ve ilaç sektörü gibi farklı alanlarda tercih edilebilecek bir sistemdir. Manyetik dişliler, bir aşırı yük torku uygulandığında sisteme zarar vermeden kayarak aşırı yüke karşı koruyucu özellik gösterirler. Sisteme uygulanan aşırı tork kaldırıldığında otomatik ve güvenli bir şekilde yeniden devreye girerek aşırı yüklere karşı doğal olarak koruma sağlarlar.

Mıknatısların güç aktarım cihazları olarak kullanılması ilk olarak 1901 yılında Armstrong tarafından, 687292 nolu patentte önerilmiştir (Armstrong, 1901). Manyetik dişli cihazlarda güç aktarımı yapısı klasik mekanik dişli kutularına benzer yapıdadır, fakat aktarım dişlilerin mekanik teması ile değil, manyetik kuvvetlerin yardımı ile gerçekleşir, en önemli fark mekanik temasın olmayışıdır (Lubin ve ark., 2010; Frank ve Toliyat, 2011; Uppalapati ve ark., 2013; Gerber ve Wang, 2013). Temel bir manyetik dişli sistemi ve mekanik dişli sistemindeki topolojik karşılığ Şekil 1'de gösterilmektedir.
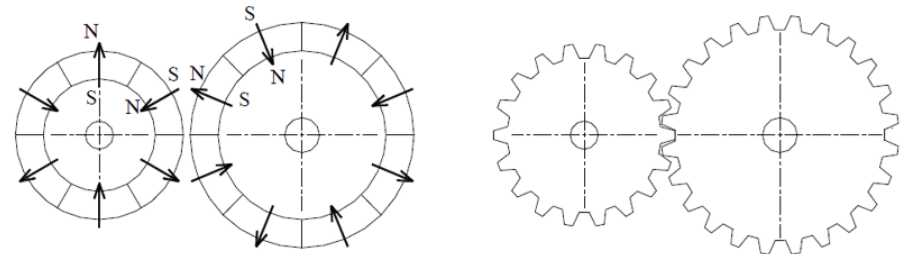

Şekil 1. Sabit mıknatıslı manyetik düz dişli şematik gösterimi ve mekanik karşılı̆̆ düz dişli
Şekil 1'de görüldüğü gibi giriş ve çıkış milinde farklı sayıda kalıcı mıknatıs manyetik dişli sistemini oluşturmaktadır. Atallah ve Howe, (2001) manyetik dişlilerin tork aktarım yoğunluklarını arttırmak için koaksiyel manyetik dişli tasarımı üzerinde çalışmalarda bulunmuşlardır. Rasmussen ve ark., (2005) koaksiyel manyetik dişli tasarımını yaparak sonlu elemanlar yöntemi ile analiz gerçekleştirmişleridir. Ayrıca koaksiyel manyetik dişli tasarımında sabit mıknatısları Halbach dizilimi ile yerleştirilerek daha yüksek tork aktarım yoğunluğu elde etmek mümkün olduğunu göstermişlerdir (Jian ve Chau, 2010). Fakat bu yapıda sabit mıknatısları açılı şekilde kutup yönleri olacak şekilde temin etmenin güçlüğü bulunmaktadır. Klasik mekanik dişli topolojisinden esinlenerek manyetik dişli tasarımı olarak mekanik eşdeğerleri elde etmek mümkündür. Dolayısı ile bir manyetik dişli, mekanik muadilinin mevcut her topolojisine göre tasarlanabilir (Tlali ve ark., 2014). Mezani ve ark. çalışmalarında manyetik dişli sistemi için eksenel alan topolojisi tanımlanmış ve maksimum tork iletimi için optimum boyutların mevcut olduğu göstermişlerdir (Mezani ve ark., 2006). Ayrıca manyetik dişli konsepti sonsuz vida ve somun içeren lineer aktüatör uygulamaları içinde tasarlanmıştır (Atallah ve ark., 2005).

Manyetik dişinin bağlı olduğu bir sistem, yağlama olmadan çalışabilmekte ayrıca, vakum veya hava geçirmez şekilde kapatılmış ortamın ihtiyaç duyulduğu ișlemlerde kullanılabilir. Temiz çalışma koşulları başta gıda sektörü olmak üzere birçok farklı sektör için tercih sebebbidr. Ayrıca benzer sistemlere göre daha uzun ömürlüdür. (Esnoz-Larraya ve ark., 2017). Bakım gerektirmeme ve temiz ortamda çalışabileme özellikleri sayesinde miko boyutlardaki manyetik dişli sistemlerinin mikro elektro-mekanik sistemlere entegre edildiği çalışmalarda güncel olarak sürdürülmektedir (Diez-Jimenez ve ark., 2018). Açık deniz rüzgâr türbini uygulamalarının ve klasik rüzgâr türbini sistemlerinde yüksek güç üretimi için, boyut ve maliyet en büyük zorluklar arasındadır. Bu sorunların üstesinden gelmek için bu, mekanik dişli donanım olmadan rüzgâr enerjisi üretimi için manyetik dişli topoloji yaklaşımı üzerine çalışılmaktadır (Belkhir ve Khenfer, 2013). Ayrıca rüzgâr türbini dişli kutuları, üretilen yüksek tork yoğunluğuna rağmen aşırı yük probleminden ve sık bakım gereksinimizden muzdariptir fakat manyetik dişli sistemleri doğası gereği aşırı tork koruma sağlamakatadır (Wei ve Aravind, 2018). Manyetik dişli sistemine stator ile elektrik sargılarını birleştirerek, motor ve redüktörün yerini alan ve geleneksel motor ve redüktörün kullanıldığı her yerde kullanılabilen kendiden redüktörlü motor sisteminde güncel çalışmalar arasında yer almaktadır (Miladinović, 2017).

Bu çalışmada koaksiyel tipteki bir manyetik dişli tasarımına yer verilmiştir. Manyetik dişli sistemleri arasında mekanik toploloji benzeri yayıngın olarak kullanıldığı için için en çok koaksiyel yapı üzerine çalışmalar bulunmaktadır (Desvaux ve ark., 2020; Park ve ark., 2020; Jing ve ark., 2019). Literatürdeki çalışmalardan farklı olarak bu çalışmada çıkış rotoru olarak sabit mıknatısların yer aldığı diş rotor yerine orta rotor olarak tasarım gerçekleştirilmiştir. Bu tasarım da giriş mili ve çıkış milinin aynı yönlü dönmesini sağlamaktadır. Dişli sisteminde yer alan sabit mıknatısların sayısı hedeflenen çevrim oranına göre belirlenmiştir. Ayrıca sistemin iki boyutlu modeli üzerinden zamana bağlı bir sonlu elemanlar analizi yapılarak 0,1 saniyelik bir süre için giriş ve çıkış millerindeki eksenel tork miktarı hesaplatılmıştır. Makaledeki manyetik dişli, fiziksel modeli çözmek için elektromanyetik sonlu eleman analizi çözümü sunan sayısal bir araç olan COMSOL Multiphysics programından yararlanılmıştır. 


\section{Koaksiyel Manyetik Dişli}

Koaksiyel manyetik dişlinin ana bileşenleri, Şekil 2'de şematik görünüşü üzerinde gösterilmiştir. Temel olarak manyetik dişli sistemi 3 adet eş merkezli rotor elamanın bir araya gelmesinden oluşur. Bunlarda iç rotor düşük sayıda sabit mıknatıs içeren sistemin en iç dönen parçasını oluşturmaktadır. Dolayısı ile iç rotor aynı zamanda giriș mili ya da yüksek hızlı mil isimleriyle de bilinmektedir. Klasik dişli topolojisinde olduğu gibi düşük tork yüksek devire sahiptir. İç rotordan hemen sonra sistemde orta kısımda sabit çelik çubukların yer aldı̆̆ 1 kısım bulunmaktadır. Bu yapı adından anlaşılacağı gibi sabit tutularak ana gövde üzerinde tutturulabileceği gibi çıkış rotoru olarakta kullanılabilir. Bu yapının sabit tutulmak yerine çıkış rotoruna bağlanması sistemin çevrim onarının değiştirmesinin yanında en önemli fark olarak çıkıș mili ile giriș milinin dönme yönlerinin aynı olmasını sağlamasıdır. Bu çalışmada literatürden farklı olarak çıkış mili olacak şekilde belirlenen orta rotor çelik çubukları sayesinde giriş ve çıkış milleri aynı yöne dönmekte ve mekanik dişlilerde olduğu gibi uygulama kolaylı̆̆ sağlamaktadır. Son olarak ise dış rotor yüksek sayıda sabit mıknatıs içeren kısım bulunmaktadır. Dış rotor aynı zamanda çıkış mili ya da düşük hızlı mil olaraktan adlandırılmaktadır. Klasik dişli topolojisinde olduğu gibi yüksek tork ve düşük devire sahiptir.

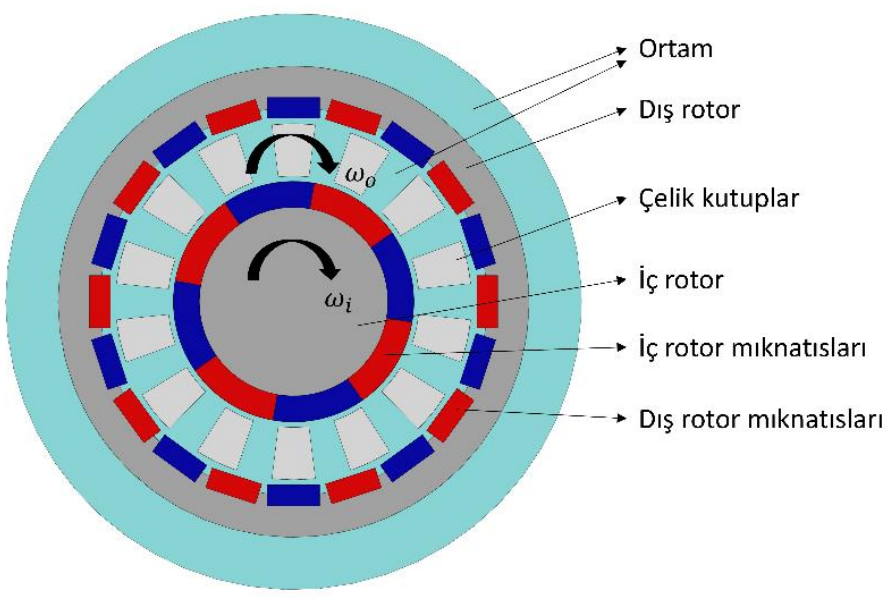

\section{Şekil 2. Bir koaksiyel manyetik dişlinin model çizimi}

Şekil 2'de verilen manyetik dişli sisteminde iç rotordaki sabit mıknatıs sayısı $n_{(P M-i)}$ dış rotordaki mıknatıs sayısı $n_{(P M-o)}$ olarak verilmiştir. Tasarlanan manyetik dişli sisteminde iç rotorda 8 adet ve diş rotorda ise 20 adet mıknatıs kullanılmıştır. Sistemde mıknatısların dizilimi için yarım Halbach yapısı seçilmiştir. Dolayısı ile 1 kutup çifti Şekil 2'de gösterimi verilen bir adet mavi bir adet kırmızı olmak üzere 2 mıknatıs çiftinden oluşmaktadır. İç ve dış rotordaki mıknatısların kutup çiftleri toplamı orta rotorda bulunan çelik çubukların sayısını vermektedir.

$$
n_{s p}=\frac{n_{P M-i}}{2}+\frac{n_{P M-o}}{2}=14
$$

Denklem (1)'de verildiği gibi sistemde 14 adet sabit çelik kutuplar bulunmaktadır. Manyetik dişli sistemi tasarımında en önemli unsur kalıcı mıknatısların seçimidir. Ark şeklindeki mıknatıslar daha pahalı olduğu için tasarımda dış rotor için dikdörtgen geometrili mıknatıslar seçilmiştir. Kullanılan mıknatısların boyutları ve manyetik dişli sisteminin diğer fiziksel ölçüleri Şekil 3 'te verilmiştir. Kalıcı mıknatıslar güçlü e-ISSN: 2148-2683 manyetik alana sahiptir, metal yapıştırma işleri için tasarlanmış epoksi yapıştırıcı kullanılarak montaj işlemi yapılmışırı. Burada iç rotorda kullanılan sabit mıknatısların iç yarıçapı $18 \mathrm{~mm}$ olarak tasarlanmıştır. İç rotor mıknatıslarından sonra yarıçapı $24 \mathrm{~mm}$, dış yarıçapı $34 \mathrm{~mm}$ olan sabit demir parçaları yerleştirilir. Bu nedenle iç rotor mıknatısları ile sabit demir direk parçaları arasında $1 \mathrm{~mm}$ hava boşluğu vardır. Dış statordaki kalıcı mıknatısların yarıçapı diktörgen mıknatısların orta noktasından geçecek şekilde $37 \mathrm{~mm}$ 'dir. Dış statorda açısal yerleştirilen dikdörtgen geometrili stator mıknatısları kullanıldığ 1 için ortalama yarıçap değeri alınmıştır. Aynı şekilde dış stator ile ortadaki sabit demir kutup parçaları arasındaki boşluk yaklaşık 1 mm'dir. Tablo 1'de manyetik dişli tasarımı için temel model parametreleri verilmiştir.

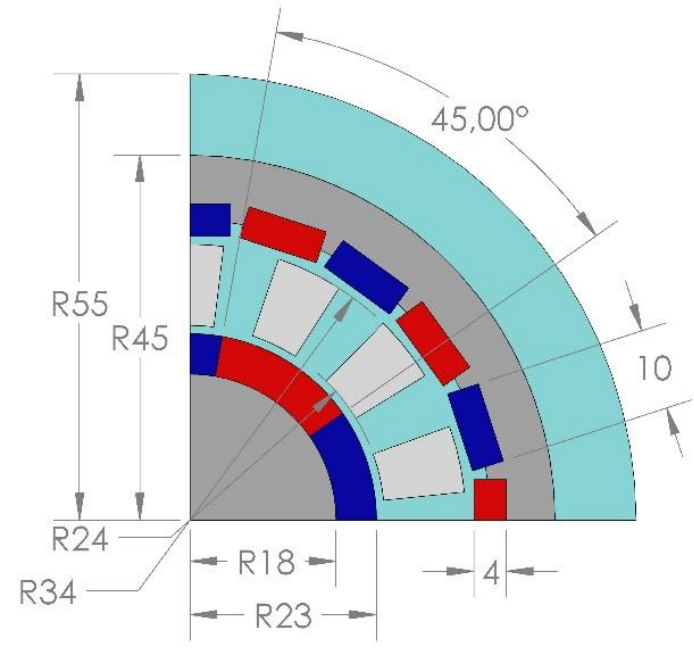

Şekil 3. Manyetik dişli sisteminin temel ölçüleri

\subsection{Dişli Çevrim Oranı}

Mekanik dişli sistemlerinde olduğu gibi manyetik dişli sistemlerinde de dişli dönme oranını belirlemek mümkündür. Dişli oranının nasıl hesaplandığını anlamak için Şekil 2'teki manyetik dişli sistemi üzerinde yer alan mıknatıs sayılarını dikkate alalım. Bu konfigürasyonda dış rotorun sabit olduğu sistemin çıkış milinin ise çelik kutuplar ile sağlandığı bir yapı söz konusudur. Dış rotorun sabitlenmiş olduğu manyetik dişli için dişli çevrim oranını veren denklem:

$$
g_{r}=\frac{\left[\frac{n_{P M-i}}{2}+\frac{n_{P M-o}}{2}\right]}{\frac{n_{P M-i}}{2}}
$$

olarak verilmiştir. Burada $g_{r}$ dişli çevrim oranını temsil etmektedir. Dolayısı ile mıknatıs sayıları yerlerine yazılarak dişli çevrim oranı 7:2 olarak bulunur. Giriş mili ile çıkış mili arasındaki nominal açısal hız ilişkisi şu şekilde formüle edilebilir:

$$
\omega_{i}=\frac{1}{g_{r}} \omega_{o}
$$

$\mathrm{Bu}$ konfigürasyon için nominal tork ilişkisi, manyetik dişli konfigürasyonu sabit bir açısal hızda çalışıyorsa ve herhangi bir kayıp yoksa, sabit güç dikkate alınarak hesaplanabilir. Sistemin toplam mekanik gücü sıfıra eşit olmalıdır. Dış rotoru sabit olduğu için açısal hızı sıfırdır, (3)'te tanımlanan nominal açısal hızlar yardımı ile tork ilişkisi şu şekilde formüle edilebilir:

$$
\tau_{i} \omega_{i}+\tau_{o} \omega_{o}=0
$$




$$
\tau_{i}=-g_{r} \tau_{o}
$$

\section{Tablo 1. Temel model parametreleri}

\begin{tabular}{c|c|l}
\hline Tanım & Değer & Açılklama \\
\hline$n_{P M-i}$ & 8 adet & İç rotor mıknatıs sayısı \\
\hline$n_{P M-o}$ & 20 adet & Diş rotor mıknatıs sayısı \\
\hline$n_{s p}$ & 14 adet & Toplam rotor uzunluğu \\
\hline$n_{\text {gear }}$ & $7: 2$ & Dişli oranı \\
\hline$\omega_{i}$ & $700 \mathrm{~d} / \mathrm{d}$ & İç rotor açısal hızı \\
\hline$\omega_{o}$ & $200 \mathrm{~d} / \mathrm{d}$ & Diş rotor açısal hızı \\
\hline$L$ & $25 \mathrm{~mm}$ & Toplam rotor uzunluğu \\
\hline$B_{r}$ & $1.4 \mathrm{~T}$ & Kullanılan mıknatısların akı yoğunluğu \\
\hline
\end{tabular}

\subsection{Prototip tasarımı}

Şekil 4 üretilen manyetik dişli sistemini göstermektedir. Ek olarak, manyetik dişli sisteminde çeşitli testler gerçekleştirmek, dişli dönüşüm oranını doğrulamak ve giriş ve çıkış torku aktarım oranlarını belirlemek gibi çeşitli çalışmaların yapılacağı için, servo motor ve kaplin elemanları yardımı ile bir test düzeneği oluşturulmuştur. Şekilde manyetik dişli sisteminin giriş ve çıkış hızları bir lazer temassız devir ölçer yardımıyla ölçülmekte ve bu değerlerin her hızda redüktörün devir hızıyla orantılı olduğu ölçülmüştür.

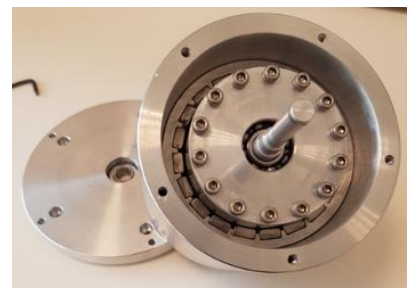

(a)

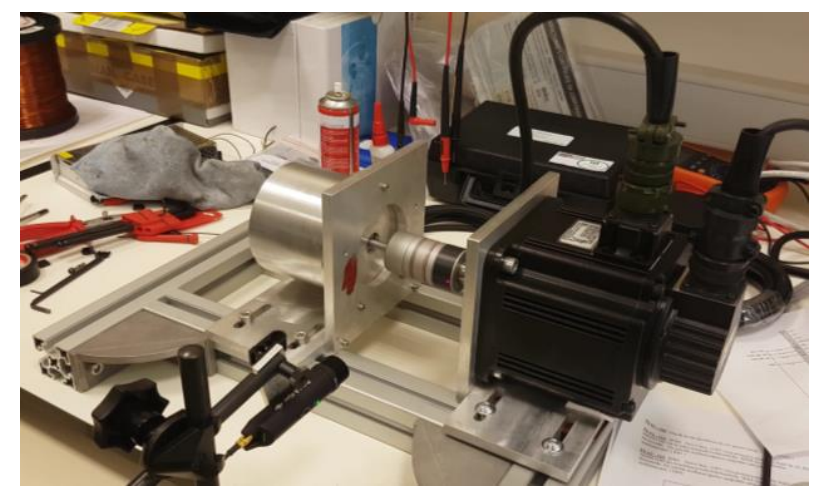

(b)

Şekil 4. (a) Manyetik dişli sistemi ve (b) test düzeneği

\section{Sonlu Elemanlar Analizi}

Sonlu elemanlar analizi için Comsol Multiphysics programında AC/DC modülü altında yer alan Rotating Machinery, Magnetics (rmm) ara yüzü kullanılarak 2 boyutlu uzayda analiz gerçekleştirilmiştir. Sistemin toplam rotor uzunluğu $(L)$ programa girilerek gerçek sistem analiz edilmiştir. Sonlu elemanlar analizi için manyetik dişli sistemine uygulanan denklemler (quasi-static) yarı statik Maxwell yasalarıdır. Maxwell denklemlerinde manyetik alan $\boldsymbol{H}$, akı yoğunluğu B ve akım yoğunluğu $\boldsymbol{J}$ ile gösterilmektedir. Dış rotorunun mıknatısların bağlandığı kısmı ve iç rotorun iç kısmı B - H eğrisinin bir enterpolasyon fonksiyonu olarak Comsol Multiphysics'te uygulanan çok düşük karbonlu demir malzeme olarak seçilmiştir. Çıkış milini temsil eden çelik kutuplar için ise Comsol kütüphanesinde bulunan Steel AISI 4340 malzemesi seçilmiştir. Son olarak kalan kısımlar için kütüphaneden standart hava malzemesi tanımlanarak uygulanmıştır. Zamana bağlı bir analiz yapılacağı için manyetik dişlide giriş mili ve çıkış milinin tanımlandığı kısımlar (moving mesh) hareketli a ğ yapısı ile oluşturulmuştur. Dolayısı ile geçiş sınır bölgesinde daha küçük eleman boyutu seçerek toplamda 27062 üçgen eleman ile Şekil 5 'te gösterilen ağ yapısı elde edilmiştir.

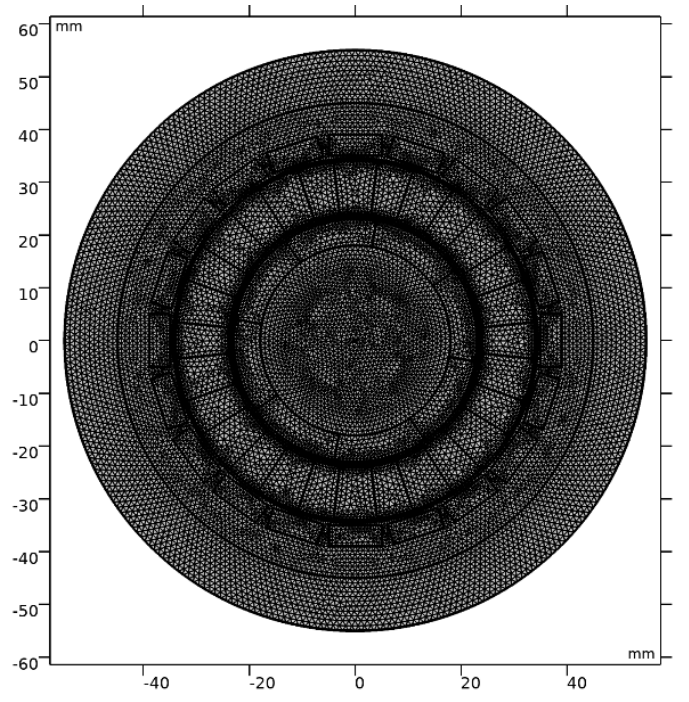

\section{Şekil 5. Manyetik dişli sisteminin sonlu elemanlar ă̆ yapısı}

Şekil 6'da manyetik dişli sistemi için $\mathrm{t}=0.1$ saniyesi için verilen manyetik akı yoğunluğu ve akı çizgileri gösterilmekledir. Orta rotorda yer alan çelik kutup parçalarında akı çizgileri yoğun ilen bu yoğunluk aynı bölgedeki hava malzemesi tanımlı bölgelerde azalmaktadır.

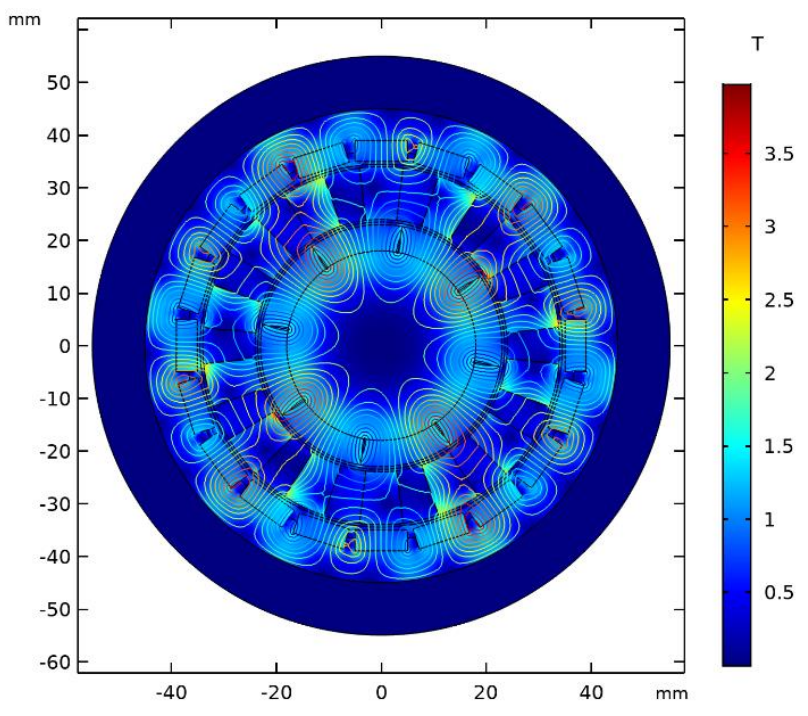

Şekil 6. Manyetik dişli sisteminin manyetik akı yoğunluğu normu ve manyetik vektör potansiyeli

Giriş milini temsil eden iç rotor ve çıkış milini temsil eden dış rotor kısmında hava harici malzemeler için tork ölçümü bölgeleri programda tanımlanmıştır. Dolayısı ile Şekil 7, giriş ve 
çıkış rotorunda üretilen eksenel torkun karşılaştırmasını göstermektedir. Orta rotorda elde edilen tork, iç rotordaki torkun yaklaşık 3,5 katıdır. Buda denklem (5)'te verilen bağıntı ile doğrulanmaktadır. Manyetik dişli rotorun üzerinde istenilen bölgelerde tanımlanan doğrular sayesinde manyetik akı yoğunlukluları elde edilebilir. Şekil 8'de sabit dış rotorun orta bölgesine kadar olan bölge için elde edilen manyetik akı yoğunluğu gösterilmektedir. Benzer şekilde çelik kutuplar (çıkış rotoru) içindeki ve iç rotor içindeki manyetik akı yoğunluğu normu Şekil 9 ve 10 da sırası ile verilmektedir.

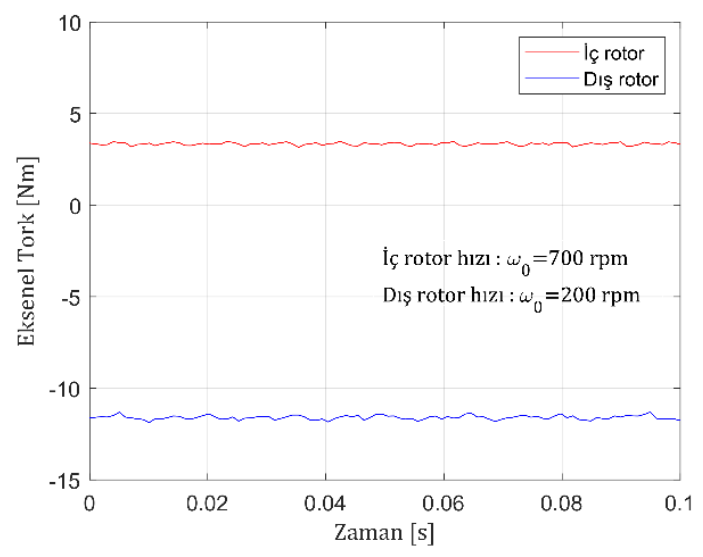

Şekil 7. Manyetik dişli sisteminin giriş mili ve çıkış mili üzerindeki tork değerleri

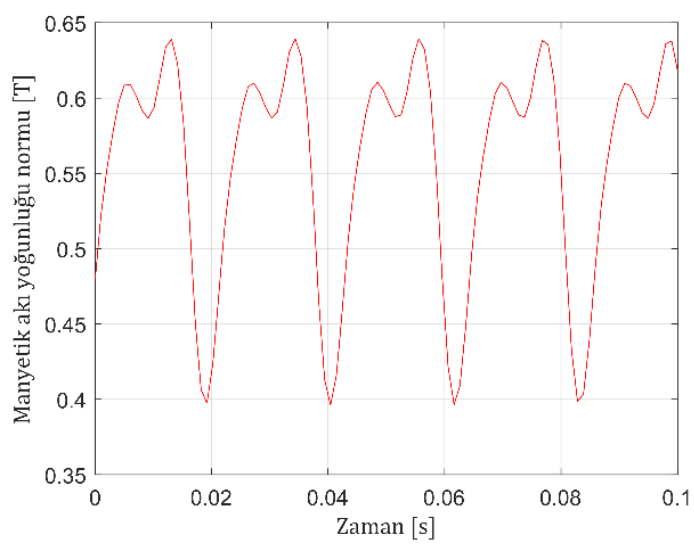

Şekil 8. Sabit dış rotor içindeki manyetik akı yoğunluğu normu

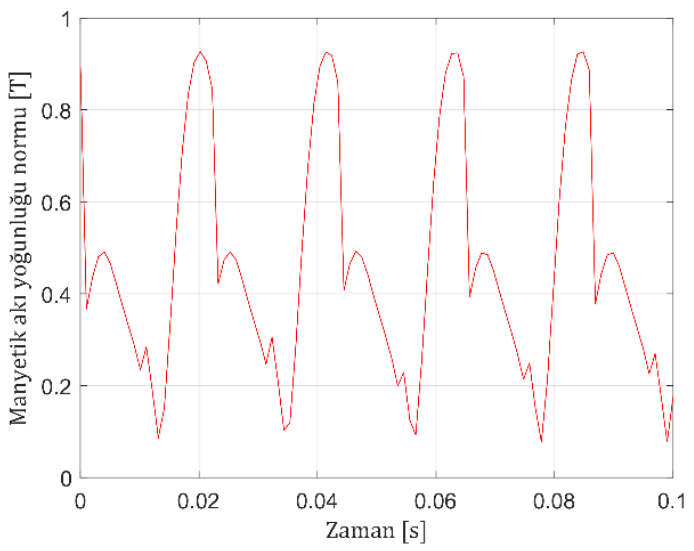

Şekil 9. Çelik kutuplar (çıkış rotoru) içindeki manyetik akı yoğunluğu normu

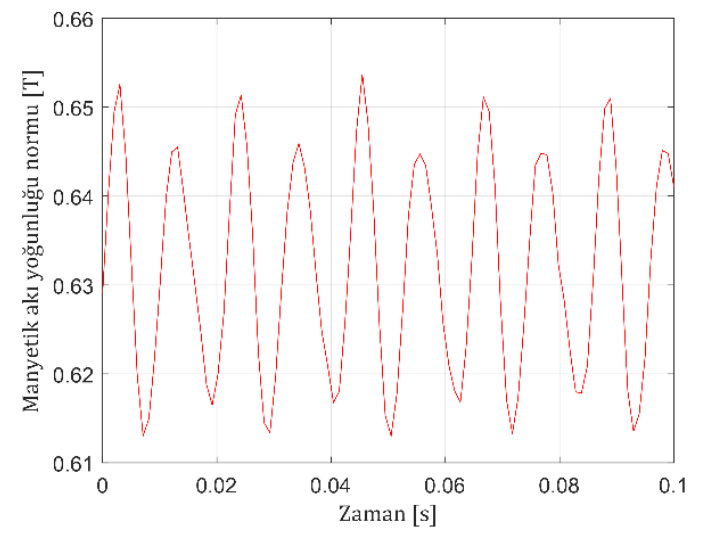

Şekil 10. İç rotor içindeki manyetik akı yoğunluğu normu

\section{Sonuç}

$\mathrm{Bu}$ çalışmada manyetik dişli sistemlerinden ve topolojilerinden bahsedilmektedir. Manyetik dişli makineler, yüksek tork yoğunluğuna sahip yeni bir elektrik makinesi sınıfı olarak ortaya çıkmıştır. Farklı topoloji önerilen manyetik dişli sistemlerinin faydalarını belirlemek ve uygulama alınını geliştirmek için daha fazla araştırmaya ihtiyaç vardır. Bazı uygulamalarda mekanik dişlilerin yerini almak için manyetik dişliler geliştirilmektedir. Mekanik dişliler gürültülüdür ve yağlama gerektirir. Manyetik dişliler ise temassız özelliğe sahip olduğundan yağlamaya gerek duymazlar. Manyetik dişliler aşırı yüklendiğinde kayma özelliği gösterirler. Manyetik dişliler, aşırı yüklenmelere karşı doğal olarak koruma sağlar ve arıza torku kaldırıldığında güvenli bir şekilde yeniden devreye girer. $\mathrm{Bu}$ avantajlar, manyetik dişlileri popüler bir konu haline getirmektedir. $\mathrm{Bu}$ çalışmada alışılagelmiş tasarımlardan farklı olarak çıkış rotorun orta kısımda bulunduğu çelik kutuplar üzerinden sağlandığı manyetik dişli tasarımına yer verilmiştir. Çalışmada bahsedilen koaksiyel manyetik dişli sisteminin üretim aşamaları da sonlu elemanlar yöntemi ile çıkış tork değerlerinin analizi ayrıca sunulmuştur.

\section{Teşekkür}

Bu çalışma 0874.TGSD.2015 numaralı Bilim, Sanayi ve Teknoloji Bakanlığı Teknogirişim Sermayesi Desteği programı kapsamında yapılmıştır.

\section{Kaynakça}

Armstrong, C. G. (1901). U.S. Patent No. 687,292. Washington, DC: U.S. Patent and Trademark Office.

Atallah, K., \& Howe, D. (2001). A novel high-performance magnetic gear. IEEE Transactions on magnetics, 37(4), 2844-2846.

Atallah, K., Wang, J., \& Howe, D. (2005). A high-performance linear magnetic gear. Journal of Applied Physics, 97(10), $10 \mathrm{~N} 516$.

Belkhir, K. S., \& Khenfer, N. (2013). Magnetic gear generator for wind energy. Prezgląd Elektrotechniczny, 5, 72-75.

Desvaux, M., Multon, B., Sire, S., \& Ahmed, H. B. (2020, August). 2 x 2D Analytical Model of a Transverse Flux Magnetic Gear. In 2020 International Conference on Electrical Machines (ICEM) (Vol. 1, pp. 565-571). IEEE. 
Diez-Jimenez, E., Sanchez-Montero, R., \& Martinez-Muñoz, M. (2018). Towards miniaturization of magnetic gears: Torque performance assessment. Micromachines, 9(1), 16.

Esnoz-Larraya, J., Valiente-Blanco, I., Cristache, C., SanchezGarcia-Casarrubios, J., Rodriguez-Celis, F., Diez-Jimenez, E., \& Perez-Diaz, J. L. (2017). Optimagdrive: Highperformance magnetic gears development for space applications. Proceedings of the ESMATS.

Frank, N. W., \& Toliyat, H. A. (2011). Analysis of the concentric planetary magnetic gear with strengthened stator and interior permanent magnet inner rotor. IEEE transactions on industry applications, 47(4), 1652-1660.

Gerber, S., \& Wang, R. J. (2013, February). Evaluation of a prototype magnetic gear. In 2013 IEEE International Conference on Industrial Technology (ICIT) (pp. 319-324). IEEE.

Jian, L., \& Chau, K. T. (2010). A coaxial magnetic gear with halbach permanent-magnet arrays. IEEE Transactions on Energy conversion, 25(2), 319-328.

Jing, L., Gong, J., Huang, Z., Ben, T., \& Huang, Y. (2019). A new structure for the magnetic gear. IEEE Access, 7, 7555075555 .

Lubin, T., Mezani, S., \& Rezzoug, A. (2010). Analytical computation of the magnetic field distribution in a magnetic gear. IEEE Transactions on magnetics, 46(7), 2611-2621.
Mezani, S., Atallah, K., \& Howe, D. (2006). A highperformance axial-field magnetic gear. Journal of applied physics, 99(8), 08R303.

Miladinović, S., Ivanović, L., Blagojević, M., \& Stojanović, B. (2017). The development of magnetic gears for transportation applications. Mobility and Vehicle Mechanics, 43(1), 39-55.

Park, E. J., Jung, S. Y., \& Kim, Y. J. (2020). Comparison of Magnetic Gear Characteristics Using Different Permanent Magnet Materials. IEEE Transactions on Applied Superconductivity, 30(4), 1-4.

Rasmussen, P. O., Andersen, T. O., Jorgensen, F. T., \& Nielsen, O. (2005). Development of a high-performance magnetic gear. IEEE transactions on industry applications, 41(3), 764770 .

Tlali, P. M., Wang, R. J., \& Gerber, S. (2014, September). Magnetic gear technologies: A review. In 2014 International Conference on Electrical Machines (ICEM) (pp. 544-550). IEEE.

Uppalapati, K. K., Bomela, W., Bird, J. Z., Calvin, M., \& Wright, J. (2013, September). Construction of a low speed flux focusing magnetic gear. In 2013 IEEE Energy Conversion Congress and Exposition (pp. 2178-2184). IEEE.

Wei, T. W., \& Aravind, C. V. (2018). Magnetic geared radial axis vertical wind turbine for low velocity regimes. In MATEC Web of Conferences (Vol. 152, p. 03007). EDP Sciences. 